\title{
Use of Technology-Based Tools in Ensuring Quality of Publishable Journal Articles
}

\author{
Gilbert C. Magulod, Jr. ${ }^{*}$ \\ University Director, Knowledge and Technology Management Office, \\ Cagayan State University, Tuguegarao, Philippines \\ https://orcid.org/0000-0001-8385-683X \\ Leonilo B. Capulso \\ City College of San Fernando, Pampanga, Philippines \\ San Matias National High School, Philippines \\ https:// orcid.org/0000-0002-2984-6590 \\ Cinder Dianne L. Tabiolo \\ Jose Rizal Memorial State University, Philippines \\ https://orcid.org/0000-0002-4565-0491 \\ Merlyn N. Luza \\ Jose Rizal Memorial State University, Philippines \\ https://orcid.org/0000-0003-3261-4632 \\ Mary Grace C. Ramada \\ Bohol Island State University- Main Campus, Philippines \\ https://orcid.org/0000-0002-4657-1867
}

\begin{abstract}
Scientific publication is a pillar that gauges the human intellectual capital of countries in the global innovation index. This paper presents the effectiveness of using technology-based tools in ensuring the quality of articles for journal publication. It employed a pre-and post-test research design to determine the effectiveness of online technology-based tools before and after the intervention. It employed a descriptive presentation of the different online technology tools used in the 21 specimens of faculty research written in publishable article formats. It examined the quality of references, level of readability, writing quality, originality, and grammar of the papers before and after the review process and interventions. The study highlighted that using the online tools improved the quality of the documents on grammar and lexical rate, similarity index, readability index, number of references, number of correct bibliographic entries for submission in high impact journals. A higher level of a cleansing process using online technology
\end{abstract}

*Corresponding author: Gilbert C. Magulod, Email: gilbertmagulod_rdecsulasam28@yahoo.com 
tools ensures the quality of publishable articles. Implications of this study will facilitate the academic community's journal article writing skill to effectively disseminate research studies results with higher chances of being accepted in respected global databases to contribute to knowledge generation and development of the country.

Keywords: journal publication; research dissemination; onlinetechnology tools

\section{Introduction}

Progress in the 21st century is impossible without research. Research is responsible for new products, new knowledge, and new ways of undertaking projects. The values of research to humanity are immeasurable. Research has proved to be an essential and powerful tool leading to human progress. The advent of the 21st century reoriented research towards good life with others to attain sustainable growth. This reorientation befitted universities around the world to be the first propellers of development in their respective countries. According to the European Commission Report (2003), there is a secure link between a scientific publication and national wealth. Within the tertiary education system, research universities play a critical role in training the professionals, high-level specialists, scientists, and researchers needed by the economy and in generating new knowledge in support of national innovation systems (Ardito et al., 2019; Dzimińska, Fijałkowska \& Sułkowski, 2020). In this setting, it is the priority of countries worldwide to ensure that their primer universities are trailblazers of intellectual and scientific development (Salmi, 2009). The competitiveness for states' intellectual capital depends on the scientific publication, patents, and knowledge generated (Arhibugi et al., 2009; Bucheli, 2012; Larsen et al., 2010). Scientific publications in reputable journals are considered for the global University ranking, times university ranking, and Shanghai World University ranking (Campos-Varela, Villaverde-Castañeda \& Ruano-Raviña, 2020; Morrison, 2017; Rauhvargers, 2011; van Nunen, Li, Reniers \& Ponnet, 2018).

Scientific journals are essential media for the dissemination of scientific findings. Research journals are coined as the "lifeblood of living and evolving science" (Gevers et al., 2006). Writing and publishing scientific articles are the way of life in scientists' careers (Adams, Rogers, Smart \& Szomszor, 2020; Ajami \& Movehedi, 2013; Dangal, Hamal \& Giri, 2017; Masters, 2013; McDowell \& Liardét, 2019; Mohammadi et al., 2018). The publication forms the basis for new research and practical application of findings and results. It can affect the scientific community and the society at large (Wager \& Kleinert, 2010), but what is lamenting is that many studies are never published and termed as the filedrawer problem (Dalton et al., 2012; Franco et al., 2014; Iwachiw, Button \& Atlas, 2019; Lane et al., 2016; Simonsohn et al., 2014; Song et al., 2010).

Academic researchers in many disciplines face difficulties in disseminating their research outputs beyond academia (Alwzinani, 2017; Dogra, 2011; Stout et al., 2006). Many academic disciplines have reported various barriers that sustain the 
gaps between academic researchers and practitioners (Drury et al., 2013; Haddow, 2011; Lanamaki et al., 2011; Tincani \& Travers, 2019). The literature shows that scholarly research outputs are buried deeply in reports and not transmitted into real practice (Waddel, 2002). Regrettably, many relevant research findings cannot reach their target audience with this kind of culture existing in the academic community (Singh \& Mayer, 2014; Jeyaraj \& Dwivedi, 2020). Many researchers are not aware of freely available online tools and guides. This paper expects to address the deplorable condition of low scientific publications among universities.

The dissemination and impact of research outputs cannot happen without those outputs being communicated to target audiences/stakeholders. Many reasons are identified why journal articles are rejected. They arise from different flaws in the research design, manuscript organization, results and discussion, conclusion (Ahlstrom, 2012; Akhtar, 2008; Fischer et al., 2017; Holschuh, 1998; Johnson, Putnam Davis, \& Bandy, 2020; Pimm, 2013; Stivers \& Cramer, 2017; Sullivan, 2015). Ezeala Nweke \& Ezeala (2013) studied the common errors in the manuscript submitted to medical science journals in Asia and Africa showed that out of 42 papers analyzed, they found crucial flaws in every section of the document. $68 \%$ have problems in the introduction and results section, $86 \%$ have deficiencies in the material and methods section while the $71 \%$ is in the discussion section. Consequently, Kapp \& Albertyn (2008) confirm that the rate of acceptance and rejection in journals are attributed to the common errors made by authors such as insufficient contextualization of the research, language style, referencing styles, date of references, originality of work, lack of focus, length of the manuscript, data analysis, plagiarism, and readability. The errors are manifold and various. Many researchers struggle to have their papers be published in high-impact journals. Uzuner (2008) also identifies problems commonly encountered in publication; among these are associated with language problems, divergence on the journal standards, parochialism, and relevance. Lamentably, despite the publication of manuscript guidelines in many high reputable journals, many manuscripts cannot meet the journal standards set and are ultimately being rejected and sent back to the author because of quality issues (Baron, 2006; ICMJE, 2010). A plethora of studies (Ezeale et al., 2013; Byrne, 2000; Bordage 2001; Person, 2004; Azer et al., 2014; Gasparyan et al., 2015; Baig et al., 2016; Hetermanet et al., 2018; Tunlid, Kristoffersson \& Åström, 2020; Radianti, Majchrzak, Fromm \& Wohlgenannt, 2020) has explored and analyzed the flaws of manuscripts why being rejected for publication in reputable high impact journals around the world.

Writing research articles for publication requires a recursive and step-by-step process coupled with useful feedback and evaluation. Outlining the structure of the material helps research writers to prepare manuscripts appropriately. The key to successful scientific writing is to start with the paper's form (IJQHC, 2004). A typical research article's basic structure follows the IMRAD sequence (Introduction, Methods, Results, and Discussion), where each of the significant components of the report addresses different aims. Figure 1 presents the 
structural element of a publishable research article adapted from Zaiger (2000)

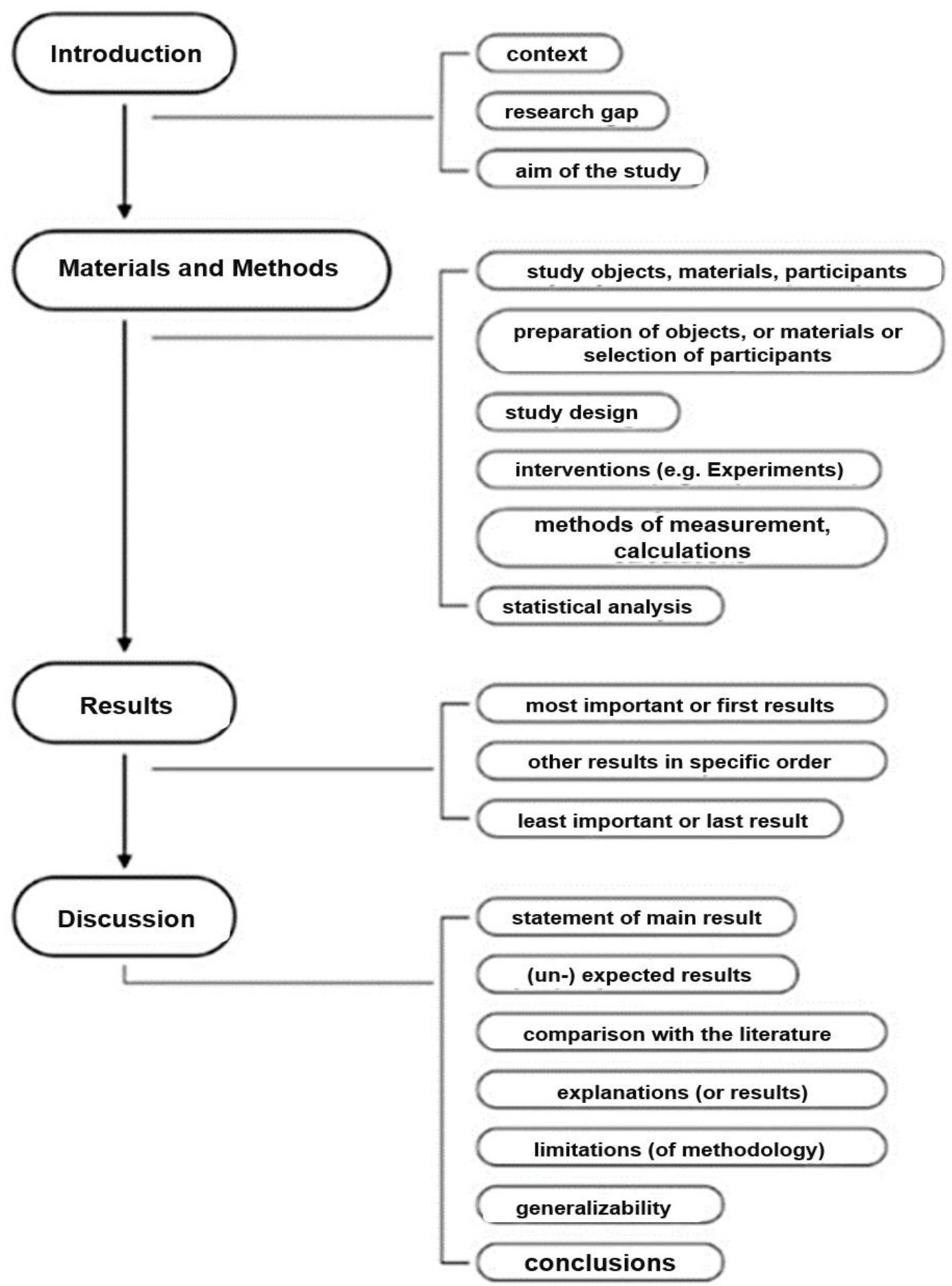

and Swales (1990) as a guide in the structure of the selected research articles.

Figure 1: Structural Component of a publishable Research Article

(Swales, 1990; Zaiger; 2000) 
This paper addresses problem among researchers by providing them information on the availability of free online tools to help establish quality journal articles. This study filled the gap to increase the acceptance rate of papers that will be submitted to respected journals. This research study's novelty fundamentally lies in the utilization and effectiveness of online technology tools in improving the quality of 21 original research studies conducted and written in the Philippines.

\section{Research Purpose}

This research study's novelty fundamentally lies in the utilization and effectiveness of online technology tools in improving the quality of 21 original research studies conducted and written in the Philippines. The purpose of this study was to present the effectiveness of online technology tools in ensuring the quality of papers using the grammar checker, plagiarism scanner, online readability scanner, citation generator, and Google scholar reference manager in improving the quality of selected articles. The 21 research papers were the research outputs of faculty members who attended the university-wide trainingwrite shop. The documents were packaged into IMRAD format (Introduction, Methods, Results, and Discussion). According to Nair and Nair (2014), most scientific papers should be prepared in an IMRAD format. The Introduction explains the scope and objective of the study in the light of current knowledge on the subject; the Materials and Methods describe how the research was conducted; the Results section reports what was found in the study, and the Discussion section explains meaning and significance of the results and provides suggestions for future directions of research. The manuscript must be prepared according to the Journal's instructions to authors.

\section{Methodology \\ Research Design}

The study fundamentally employed pre-and post-test design to determine the effectiveness of online technology-based tools before and after using technology tools. The quality indicators of the articles were measured before and after the usage of the technology tools. Salkind (2010) noted that the critical premise behind the use of pre-test -post-test design involves obtaining the pre-test measure of the outcome before administering the intervention, followed by a post-test of a similar effort after the intervention or treatment is implemented.

To ensure the quality of the quality of the research articles, selection criteria were set, the papers: (1) must have been completed papers that were institutionally/ externally funded for the past three years (2016-2019); (2) must not have been submitted for paper publication or under consideration to journals. Manuscript authors' names were removed and replaced with codes to ensure confidentiality. The sample size of 21 was only based on availability during the study's time. The study protocol was reviewed and approved. The study's conduct lasted for three days during the publication training write shop conducted by the Knowledge andTechnology Management Office of the Research, Development, and Extension Unit of one public higher education 
institution in the Philippines. The three-phase implementation process was employed.

\section{Sample and Data Collection \\ Phase 1. Before the Intervention}

Before starting the intervention, a university-wide publication training write shop was conducted for the faculty members who have completed research papers for three years. The publication write shop aims to package faculty researchers' reports in the University for higher chances of publication in Scopus and Thomson Reuters ISI. The participating faculty members were required to submit research articles in IMRAD format before the training. The participants were informed of the purpose of the activity. They were also told of the expected output for the publication training write shop. The 21 papers were scanned by the researcher using different technology tools such as a grammar checker, a plagiarism scanner, a readability test, several references, and correct bibliographic entries. Scores and percentages were recorded as the precalculated data.

\section{Phase 2. During the Intervention}

During the implementation phase, the researcher introduced different technology tools for publication. The participants were oriented to using grammar checkers, a plagiarism scanner, a readability test, several references, and correct bibliographic entries. They were provided a hands-on demonstration and walk-through sessions. The intervention period lasted for two days. The participants were provided with online links to different technology tools. The soft wares were installed on their personal computers. During the implementation period, the researcher instructed the participants to let their papers be processed using different online technology tools. The participants were requested to come up with the documents' necessary revisions based on the scores and percentages shown by the different technology tools. They were given one day to make the revisions.

\section{Phase 3. After the Intervention}

After implementing the different technology tools and necessary revisions of papers done by the participants, their writings were locally peer-reviewed by experts and researchers in the university with publications in reputable journals - the provided feedback for the improvement of the papers. After the peer review was documented, the author requested the articles to be scanned using the different technology tools. The researcher, as post-calculated data, recorded the post result of the documents.

\section{Measurement and Analysis of Variables}

To analyze the gathered data from the research papers, descriptive statistics such as frequency count, mean, and percentage were used. Inferential statistics using the paired sample t-test was utilized to identify the difference between the pre-scores and post-scores of the 21 selected papers. Frequency count was used to analyzing the results of the grammar checker along with the contextual spelling, grammar punctuation, and sentence structure. The total number of 
alerts were recorded. Meanwhile, a plagiarism scanner was utilized to get the percentage of similarity index. The rate of plagiarism is from $0 \%$ to $100 \%$. The readability index of the paper was measured using an automatic readability checker having the following score of $0-100 \%$ with the following interpretation: 90-100 very easy; 80-89 \% easy, 70-79 fairly easy; 60-69 standard; 50-59- moderate difficulty; 30-49- Difficult; 0-29- very confusing. As to the number of references and the number of bibliographic entries, the researcher manually counted errors. The pre-and post-scores were tabulated and subjected to appropriate statistical tools to arrive at the result's interpretation and discussion.

\section{Results and Discussion}

\section{Technology-Based Tools in Writing Article for Publication}

The adoption of online technology tools provided a better quality of the papers. Having adequate knowledge and skill in using the different online technology tools will eventually increase publication likelihood in reputable journals. Submitting articles for journal publication is a competitive race since many papers are being introduced to other journals. Therefore, only the best manuscripts being submitted get the editors' attention. This portion of the article presents the various online technology tools utilized in the study to ensure the manuscripts' quality standards. Table 1 shows the online links of the different technology tools, namely Google Scholar, Grammarly, Plagscan, online citation generator, and online readability tool.

Table 1. Online- Technology Tools

\begin{tabular}{|c|l|}
\hline $\begin{array}{c}\text { Technology-Based } \\
\text { Tools }\end{array}$ & \multicolumn{1}{c|}{ Online Links } \\
\hline 1. Google Scholar & $\underline{\text { https://scholar.google.com.ph/ }}$ \\
\hline 2. Grammarly & $\underline{\text { https://www.grammarly.com }}$ \\
\hline 3. PlagScan & $\begin{array}{l}\underline{\text { https://smallseotools.com/plagiarism- }} \\
\text { checker/ }\end{array}$ \\
\hline $\begin{array}{l}\text { 4. Online Citation } \\
\text { Generator }\end{array}$ & $\underline{\text { http://www.citationmachine.net/ }}$ \\
\hline $\begin{array}{l}\text { 5. Automatic } \\
\text { readability Tool }\end{array}$ & $\underline{\underline{\text { http://www.readabilityformulas.com/free- }}}$ \\
\hline
\end{tabular}

Google Scholar is a freely accessible search engine for scholarly literature. It contains articles, theses, abstracts, books, and court opinions from various sources such as online repositories, academic publishers, universities, professional societies, and other web sites. Such software provides scholarly works across the world. The Google scholar also effectively explores citations, related works, publications, and authors. It locates the original links of the documents. It also has the advantage of keeping recent developments in the different research areas while one can cite publications and make a Google scholar author profile. MacEachen (2016) recommends using Google Scholar for 
literature in evidence-based dentistry searching, highlighting seven effective techniques and features in using it.

Grammarly is a cloud-based software developed by Grammarly Inc. It is an English-language writing-enhancement platform that was released in 2009 intended for checking manuscript write-ups. It is also equipped with a plagiarism-detection tool and proofreading resources with more than 250 rules in the grammar. This online software automatically detects errors in grammar, word choice, punctuation, spelling, and writing style. It is equipped with algorithms, flag issues that suggest auto-corrections for grammar, style, spelling, punctuation, wordiness, and plagiarism (Moore, 2018; Pawlak, 2020; Chen, Xie \& Hwang, 2020).

Google Online Citation is a free search engine for Google scholar. It guides researchers to properly cite a book, magazines, news, website, Journal, case studies, synthesis papers, methodical articles, trade publications, etc., using APA, MLA, Chicago, and more. Having proper citations in the reference section of the report allows the researcher to give credit to the scholarly works of other researchers in the field as well making the readers of the article distinguish which ideas are personally owned and borrowed by the researcher guiding the readers to trace the philosophical ideas being presented (Bradley, 2011). The field of specialization of the writer also requires them to follow citation styles.

The online readability tool calculates the words, syllables, number of sentences, and other characters in the article. This tool allows the writer to identify the reading level of the text. It also provides feedback if the possible audience can read the material well. The tool is useful since it makes the paper to be easily understood by scientific and non-science people, which is an offshoot of article impact. The readability of a journal article is an essential component of scientific reading. The readability describes the easiness with which a research article can be read. Plavén-Sigray et al. (2017) confirm that in scientific reporting, clear and accurate reporting is an essential part of the scientific process. Clarity of written text can be easily quantified using readability formulas to estimate the articles (Flesh, 1948; DuBay, 2004; Stajner et al., 2012).

\section{Quality Indicators of the Papers before and After the Coaching Interventions using the Technology Tools \\ The utilization of the different technology-based tools before and after the intervention shows the following quality indicators of the papers, namely: Grammar and lexical quality, similarity index, readability index, number of references, number of correct bibliographic entries.}

\section{Effectiveness of Online Grammar Checker}

Table 2 shows the difference in the grammar errors of the 21 papers before and after the intervention. The data shows that before implementing the intervention, the 21 documents obtained 132.85 errors along with misspelled words, incorrect punctuation, and lexical errors. After the intervention, there were only 21.28 grammar errors shown. The result showed a significant 
difference in the scores before and after the grammar checker's utilization as presented with the computed $t$ value of 12.986 and $p$-value of 0.000 , which is lower than the alpha value of 0.01 .

Table 2. The difference in the grammar quality of the manuscripts using grammar checker before and after the intervention

\begin{tabular}{|c|c|c|c|c|c|c|}
\hline & $\begin{array}{c}\text { Mean Score } \\
(\mathbf{n}=\mathbf{2 1})\end{array}$ & SD & $\begin{array}{c}\text { Mean } \\
\text { Diff }\end{array}$ & t-value & df & P value \\
\hline Before & 132.85 & 42.17 & \multirow{2}{*}{111.57} & 12.968 & 20 & $0.00^{* *}$ \\
\hline After & 21.28 & 9.10 & &
\end{tabular}

Sig. (2-tailed)

** (significant at 0.01 alpha level)

It presents that after using the online grammar checker, the papers obtained a significantly lower number of errors in the manuscript. This, however, shows that using an online proofreading checker will help facilitate a better quality of papers for publication. As an online proofreading tool, it scanned the articles for grammar errors and mistook, increasing the articles' writing quality. The writing quality of papers in the scientific publications has been one of the critical issues why high impact journals reject the paper for publication. Correct spelling, grammar, and punctuation are predictors of writing success (Daffern, Mackenzie \& Hemmings, 2017; Rozovskaya and Roth, 2010; Tetreault and Chodorow, 2008). In the scientific publication, it is essential to note that it is the author's responsibility to have the correct language of the manuscript, making it in the best possible form that would relate to the concord of grammar and spelling (Griffies et al., 2013). Grammarly tools help to prevent mistakes and improve writing skills (Sing \& Mayer, 2014). Mungra \& Webber (2010) investigated the peer review process in medical research found out that lexical and grammatical mistakes, clarity, and word counts are the frequent comments and criticism of peer reviewers.

\section{Effectiveness of Online Plagiarism Scanner}

Table 3 reveals the similarity index of the papers before and after the use of a plagiarism scanner. The data shows that before implementing the technology, a mean of $60.04 \%$ of the similarity index was found. After the implementation, only $20.71 \%$ of a similar index of the papers was found, showing an acceptable paper publication rate. The lower level of similarity index increases the likelihood of an article published in respected journals. The intervention provided the participants to reduce the percentage of similarity index.

Table 3. The difference in Similarity Index

Before and after the intervention

\begin{tabular}{|c|c|c|c|c|c|c|}
\hline & $\begin{array}{c}\text { Mean Score } \\
(\mathbf{n}=\mathbf{2 1})\end{array}$ & SD & Mean Diff & t-value & df & P value \\
\hline Before & 60.04 & 14.12 & \multirow{2}{*}{39.33} & 11.503 & 20 & $0.00^{* *}$ \\
\hline After & 20.71 & 4.80 & & \\
\hline
\end{tabular}

Sig. (2-tailed)

** (significant at 0.01 alpha level) 
Plagiarism detection software already predicts scientific articles' quality for publication (Bazdaric, 2012; Martin, 2005; Naik, Landge, \& Mahender, 2015). Tools that detect plagiarism are useful for the academic and scientific community. Since scientific publication is an ultimate output of scientists, they are obliged to adhere to the ethical, legal, and moral standards acceptable for the scientific community (Masic, 2011 \& Masic et al., 2004). Fraudulent results and plagiarized text corrupt scientific literature's essence (Sharma \& Singh, 2011; Lykkesfeldt, 2016). In the study of Stretton et al. (2012), papers are being retracted because of misconduct and plagiarism.

\section{Effectiveness of Online Readability Tool}

Table 4 presents the readability index of the papers before and after using an online readability tool. It can be seen from the data that before the implementation of the intervention, an average score of $30.47 \%$ showing a problematic level of readability among the selected articles. After the implementation, a standard level of 60 readability index was found, making a better quality of the papers. The readability of articles increases the chance of acceptance in journal publication. The readability of the article constitutes its style and comprehensiveness to bring its scientific essence to the world.

Table 4. The difference in Readability Index before and after the intervention

\begin{tabular}{|c|c|c|c|c|c|c|}
\hline & $\begin{array}{c}\text { Mean Score } \\
(\mathbf{n}=\mathbf{2 1})\end{array}$ & SD & $\begin{array}{c}\text { Mean } \\
\text { Diff }\end{array}$ & t-value & df & P value \\
\hline Before & 37.47 & 12.56 & -22.38 & -6.636 & 20 & $0.00^{* *}$ \\
\hline After & 60.00 & 9.07 & -2076 \\
\hline
\end{tabular}

Sig. (2-tailed)

** (significant at 0.01 alpha level)

Journal articles should keep practitioners informed on the current trend and development in their field of specialization. A well-published report should be easily understood by others to effectively and completely comprehend its content (Lee \& French, 2011; Otto et al., 2010; Garcia-Merino et al., 2009). Likewise, Gyasi (2017) affirmed that academic journals are vehicles of information in which the research findings are presented. In the study of Severance and Cohen (2015), they examined the readability of medical journals found out that the difficulty level of reading abstract medical journals raised issues on the accessibility of medical research to reach the wider audience. Therefore, readability is a metric that successfully brings information to large groups of people (Ojha et al., 2018; Brtka et al., 2016).

\section{Effectiveness of Google Scholar Reference Manager}

As presented in Table 5, it shows that before implementing Google scholar referencing a mean count of 21.42 showing a limited number of references in the articles, an average of 41.80 references is seen after the performance. This implies a significant difference in the number of concerns before and after the intervention with the computed p-value of 0.00 . The intervention increased the number of credible references in the articles of the participants significantly. The 
number and quality of connections cited to increase the likelihood of journal article accepted for publication.

Table 5. The difference in the number of references before and after the intervention

\begin{tabular}{|c|c|c|c|c|c|c|}
\hline & $\begin{array}{c}\text { Mean Score } \\
(\mathbf{n = 2 1})\end{array}$ & SD & $\begin{array}{c}\text { Mean } \\
\text { Diff }\end{array}$ & t-value & df & P value \\
\hline Before & 21.42 & 9.36 & -20.38 & -7.804 & 20 & $0.00^{* *}$ \\
\hline After & 41.80 & 10.75 & -204 \\
\hline
\end{tabular}

Sig. (2-tailed)

** (significant at 0.01 alpha level)

The use of Google scholar reference manager improved the quality of the articles in its reference section. Google Scholar is a powerful online tool for searching the scientific literature. It allows for quick search and access to the materials for specific fields, journals, date of publication, authors, keywords, related literature, abstract, and citations. Google Scholar is a web-based search engine cataloging millions of records coming from academic and grey literature. It collated results on the internet, which is free of use. Haddaway et al. (2015) found that GS search results have a high level of transparency and capacity to update and provide critical systemic reviews since the literature search is an integral component of the research endeavor. It is capable of delivering literature for a specific study. As a search engine, Google scholar is used to searching synthesis papers, methodical articles, original articles, trade publications, case studies, online books, commentaries, patents, etc. (Reed et al., 2015; Hughes et al., 2014; Roe et al., 2014). Gehanno et al. (2013) studied the sufficiency of Google scholar for systematic reviews in medicine found that it is an excellent bibliographic database for systematic reviews. Researchers should use online references to look for relevant reviews of related studies and literature. The quality of papers being submitted for publication depends on the quality and number of references cited to establish the paper's scientific grounding.

\section{Effectiveness of Citation Generator}

Table 6 shows the effectiveness of an online citation generator on the quality of the articles. Before the intervention, an average of 6.33 bibliographic errors was traced. After the use of a citation generator, only 0.85 errors were left. It is showing a p-value of 0.000 . It means that it significantly improved the bibliographic entries of the papers. Proper citation is a good quality indicator of an article for publication.

Table 6. The difference between the Number of Correct Bibliographic Entries before and after the intervention

\begin{tabular}{|c|c|c|c|c|c|c|}
\hline & $\begin{array}{c}\text { Mean Score } \\
(\mathbf{n}=\mathbf{2 1})\end{array}$ & SD & $\begin{array}{c}\text { Mean } \\
\text { Diff }\end{array}$ & t-value & df & P value \\
\hline Before & 6.33 & 0.96 & \multirow{2}{*}{5.476} & 16.68 & 20 & $0.00^{* *}$ \\
\hline After & 0.85 & 0.91 & &
\end{tabular}

Sig. (2-tailed)

** (significant at 0.01 alpha level) 
Google scholar effectively provides citations for articles. It gives APA, MLA, Chicago, Vancouver, or Turabian as referencing styles depending on what the Journal requires the author to use. The quote shown in the Google Scholar search results will easily allow the researchers to get an accurate citation of papers included in the bibliographic entries. The citation is the list of formal references to online, print, published, or unpolished sources that the author obtained while writing it (Labaree, 2009). A proper way of citation will allow the audience to find the materials used by the author. An effective technique to locate relevant and useful sources for a research topic is to follow the references coming from credible sources. It suggests that researchers must determine the facts, theories, laws, concepts, and ideas derived from others. Errors in paper citation hinder scholarly communication's effectiveness, creating an adverse effect on the academic and scientific communities (Setyawan et al., 2020; Madhusudhan, 2016; Faunce \& Job, 2001, Lee \& Lin, 2013). Conrad, Leonard \& Somerville (2015) examined the effectiveness of citation generation tools concluded that they provided efficient and effective research practices among researchers.

\section{Conclusion}

This paper suggests using online technology tools to facilitate the quality of articles to be submitted for publication. Research publication as global scholar merchandise requires authors to write well-prepared manuscripts that will be read by a broad audience. This paper assessed the effectiveness of using online technology tools to ensure quality standards of the documents and grammar, referencing, citation, and originality. Using a pre-post experimental design, 21 full-length research articles were selected. The study highlighted that using the online grammar checker, a plagiarism scanner, online readability scanner, citation generator, and Google scholar reference manager improved the quality of the papers on grammar and lexical quality, similarity index, readability index, number of references, number of correct bibliographic entries for submission in high impact journals. Implications of this study will further develop the research writing competence of the academic community to creatively and effectively disseminate the results of their research studies with higher chances of being accepted in respected global databases as their contribution to knowledge generation and development of the country in terms of scientific publication as the measurement of human intellectual capital.

\section{Limitations and implications}

Limitation of the present study: A small number of articles were only considered and only limited to a short period. As future research directions, another analysis may be conducted using the online technology tools and track how many papers will be accepted in an actual journal submission. Notwithstanding the limitations, this study highlights researchers' necessary actions to encourage them to utilize free available quality assurance tools to establish a higher quality of their papers, promoting a robust research culture of universities. This study could serve as a useful reference to improve manuscript preparation and organization. Additionally, other available software tools ensure the quality of research articles and improve the article's quality. Nevertheless, the technology 
tools utilized in the study must not be seen as the mandatory regulations in which researchers and students must use for scientific writing. They are still encouraged to opt for possible best strategies which suit their interest and habits.

\section{References}

Adams, J., Rogers, G., Smart, W., \& Szomszor, M. (2020). Longitudinal variation in national research publication portfolios: Steps required to index balance and evenness. Quantitative Science Studies, 1(3), 1182-1202. https://doi.org/10.1162/qss_a_00073

Ahlstrom, D. (2012). Several key reasons why a paper is likely to be rejected at the Asia Pacific Journal of Management. https://doi.org/10.1007/s10490-012-9315-7

Ajami, S., \& Movahedi, F. (2013). Challenges for authors and publishers in scientific journal. Paskistan Journal of Medical Sciences, 29(1), 432-436. http://dx.doi.org/10.12669/ pjms.291(Suppl).3550

Akhtar, J. (2008). Why Articles get rejected at JCPSP: Myths and realities. Journal of the College of Physicians and Surgeons Pakistan, 18(10), 599-600.

Alden, J., \& Lin, G. (2004). Benchmarking the characteristics of a world-class university: Developing an international strategy at university level. Leadership Foundation for Higher Education, Londres.

Archibugi, D., Denni, M., \& Filippetti, A. (2009). The technological capabilities of nation ns: The state of the art of synthetic indicators. Technological Forecasting and Social Change, 76(7), 917-931. https://doi.org/10.1016/j.techfore.2009.01.002

Ardito, L., Ferraris, A., Petruzzelli, A. M., Bresciani, S., \& Del Giudice, M. (2019). The role of universities in the knowledge management of smart city projects. Technological Forecasting and Social Change, 142, 312-321. https://doi.org/10.1016/j.techfore.2018.07.030

Azer, S. A., Dupras, D. M., \& Azer, S. (2014). Writing for publication in medical education in high impact journals. Eur Rev Med Pharmacol Sci, 18(19), 66-81.

Baig, S., Ahmed, S., \& Antique, H. (2016). Reviewing a manuscript: disparity amongst peer reviewers priorities from basic health sciences and clinicians. Journal of the College of Physicians and Surgeons Pakistan, 26(8), 677-680. https://www.jcpsp.pk/archive/2016/Aug2016/10.pdf

Baždarić, K. (2012). Plagiarism detection-quality management tool for all scientific journals. Croatian medical journal, 53(1), 1-3. https://doi.org/10.3325/cmj.2012.53.1

Bordage, G. (2001). Reasons reviewers reject and accept manuscripts: the strengths and weaknesses in medical education reports. Academic Medicine, 76(9), 889-896. https://journals.lww.com/academicmedicine/Fulltext/2001/09000/Reasons_R eviewers_Reject_and_Accept_Manuscripts_.10.aspx

Bradley, C. (2011). Plagiarism education and prevention: A subject-driven case-based approach. Elsevier.

Brtka, V., Berkovic, I., Ognjenovic, V., Brtka, E., Martinov, D., \& Stojkovic-Jovanovic, T. (2016). Improving Readability of Medical Data by Using Decision Rules.

Bucheli, V., Díaz, A., Calderón, J. P., Lemoine, P., Valdivia, J. A., Villaveces, J. L., \& Zarama, R. (2012). Growth of scientific production in Colombian universities: an intellectual capital-based approach. Scientometrics, 91(2), 369-382. https:// doi.org/10.1007/s11192-012-0627-7

Byrne, D. W. (2000). Common reasons for rejecting manuscripts at medical journals: A survey of editors and peer reviewers. Science Editor, 23(2), 39-44. Retrieved from 
https://www.councilscienceeditors.org/wp-content/uploads/v23n2p039044.pdf

Campos-Varela, I., Villaverde-Castañeda, R., \& Ruano-Raviña, A. (2020). Retraction of publications: a study of biomedical journals retracting publications based on impact factor and journal category. Gaceta sanitaria, 34(5), 430-434. https://doi.org/10.1016/j.gaceta.2019.05.008

Chen, X., Xie, H., \& Hwang, G. J. (2020). A Multi-Perspective Study on Artificial Intelligence in Education: Grants, Conferences, Journals, Software Tools, Institutions, and Researchers. Computers and Education: Artificial Intelligence, 100005. https://doi.org/10.1016/j.caeai.2020.100005

Conrad, L. Y., Leonard, E., \& Somerville, M. M. (2015). New pathways in scholarly discovery: understanding the next generation of researcher tools. Retrieved from https://eprints.qut.edu.au/109219/

Daffern, T., Mackenzie, N. M., \& Hemmings, B. (2017). Predictors of writing success: How important are spelling, grammar and punctuation?. Australian Journal of Education, 61(1), 75-87. https://doi.org/10.1177/0004944116685319

Dangal, G., Hamal, P. K., \& Giri, M. (2017). Understanding Research and Scientific Publication. Journal of Nepal Health Research Council, 15(1).

Dogra, S. (2011). Why your manuscript was rejected and how to prevent it?. Indian Journal of Dermatology, Venereology, and Leprology, 77(2), 123.

DuBay, W. H. (2004). The Principles of Readability. Impact Information: Costa Mesa. Retrieved from https://eric.ed.gov/?id=ED490073

Dzimińska, M., Fijałkowska, J., \& Sułkowski, Ł. (2020). A Conceptual Model Proposal: Universities as Culture Change Agents for Sustainable Development. Sustainability, 12(11), 4635. https://doi.org/10.3390/su12114635

EU-Commission. (2003). Third european report on science and technology indicators. Towards a knowledge-based economy. Technical report, Brussels: DirectorateGeneral for Research.

Faunce, G. J., \& Soames Job, R. F. (2001). The accuracy of reference lists in five experimental psychology journals. American Psychologist, 56(10), 829. https:// doi.org/10.1037/0003-066X.56.10.829

Fischer, E., Gopaldas, A., \& Scaraboto, D. (2017). Why papers are rejected and how to get yours accepted: Advice on the construction of interpretive consumer research articles. Qualitative Market Research: An International Journal, 20(1), 60-67. https://doi.org/10.1108/QMR-06-2016-0051

Franco, A., Malhotra, N., \& Simonovits, G. (2014). Publication bias in the social sciences: Unlocking the file drawer. Science, 345(6203), 1502-1505. https://doi.org/10.1126/science.1255484

García-Merino, T., \& Santos-Alvarez, V. (2009). Characterizing the top journals in strategic management: orientation, style, originality, and readability. Journal of Scholarly Publishing, 40(4), 420-439. https://doi.org/10.3138/jsp.40.4.420

Gasparyan, A. Y., Yessirkepov, M., Voronov, A. A., Gerasimov, A. N., Kostyukova, E. I., \& Kitas, G. D. (2015). Preserving the integrity of citations and references by all stakeholders of science communication. Journal of Korean medical science, 30(11), 1545-1552. https://doi.org/10.3346/jkms.2015.30.11.1545

Gehanno, J. F., Rollin, L., \& Darmoni, S. (2013). Is the coverage of Google Scholar enough to be used alone for systematic reviews. BMC medical informatics and decision making, 13(1), $7 . \quad$ Retrieved https://link.springer.com/article/10.1186/1472-6947-13-7

Gevers, W., Mati, X., Mouton, J., Page-Shipp, R., Hammes, M., \& Pouris, A. (2006). Conclusions and recommendations for a strategically enhanced role of research 
publishing in South Africa. Report on a strategic approach to research publishing in South Africa, 107.

Griffies, S. M., Perrie, W. A., \& Hull, G. (2013). Elements of style for writing scientific journal articles. Publishing Connect, Elsevier. Retrieved from https://virayeh.com/SampleDoc/Virayeh20153204.pdf

Gyasi, W. K. (2017). Taylor and Francis Journals under the critical lens of readability analysis. AFRREV IJAH: An International Journal of Arts and Humanities, 6(2), 1-14. Retrieved from https://www.ajol.info/index.php/ijah/article/view/157087

Haddaway, N. R., Collins, A. M., Coughlin, D., \& Kirk, S. (2015). The role of Google Scholar in evidence reviews and its applicability to grey literature searching. PloS one, 10(9), e0138237. https:/ / doi.org/10.1371/journal.pone.0138237

Haddow, G. (2010). Communicating research to practice: The role of professional association publications. Library and Information Research, 34(108), 33-44. https:// doi.org/10.29173/lirg332

Holschuh, J. L. (1998). Why manuscripts get rejected and what can be done about it: Understanding the editorial process from an insider's perspective. Journal of $\begin{array}{llll}\text { Literacy } \quad \text { Research, } & \text { 30(1), }\end{array}$ https://journals.sagepub.com/doi/pdf/10.1080/10862969809547979

Hughes, K. M., Kaiser, M. J., Jennings, S., McConnaughey, R. A., Pitcher, R., Hilborn, R., \& Rijnsdorp, A. (2014). Investigating the effects of mobile bottom fishing on benthic biota: a systematic review protocol. Environmental evidence, 3(1), 23. https://environmentalevidencejournal.biomedcentral.com/articles/10.1186/20 47-2382-3-23

International Committee of Medical Journal Editors. Uniform requirements for manuscripts submitted to biomedical journals: Writing and editing for biomedical publication. 2010. Retrieved from http://www.icmje.org/urm_full.pdf

Iwachiw, J. S., Button, A. L., \& Atlas, J. (2019). The perceived role of null results in school psychology research and publication. School psychology international, 40(4), 416430. https://doi.org/10.1177/0143034319851230

Jeyaraj, A., \& Dwivedi, Y. K. (2020). Meta-analysis in information systems research: Review and recommendations. International Journal of Information Management, 55, 102226. https://doi.org/10.1016/j.ijinfomgt.2020.102226

Johnson, M. E., Putnam Davis, J., \& Bandy, S. (2020). Bridging the gap: sustaining publication of a newly created undergraduate research journal. The serials librarian, 78(1-4), 149-154. https://doi.org/10.1080/0361526X.2020.1696622

Kapp, C., \& Albertyn, R. (2008). Accepted or rejected: editors' perspectives on common errors of. Acta Academica, 40(4), 270-288.

Labaree, R. V. (2009). Research Guides: Organizing Your Social Sciences Research Paper: Qualitative Methods. Retrieved from https:/ /libguides.usc.edu/c.php?g=235034\&p=1559822

Lanamäki, A., Stendal, K., \& Thapa, D. (2011). Mutual informing between IS academia and practice: insights from KIWISR-5. AIS. Retrieved from http:/ / hdl.handle.net/11250/136299

Lane, A., Luminet, O., Nave, G., \& Mikolajczak, M. (2016). Is there a publication bias in behavioural intranasal oxytocin research on humans? Opening the file drawer of one laboratory. Journal of neuroendocrinology, 28(4). https://doi.org/10.1111/jne.12384

Larsen, P., \& Von Ins, M. (2010). The rate of growth in scientific publication and the decline in coverage provided by Science Citation Index. Scientometrics, 84(3), 575603. https://doi.org/10.1007/s11192-010-0202-z 
Lee, C. J., \& Lin, W. Y. C. (2013). Citation Errors in the Masters' Theses of the Library and Information Science and Information Engineering. Journal of Library $\mathcal{E}$ Information Studies, 11(1).

Lee, S., \& French, N. (2011). The readability of academic papers in the Journal of Property Investment \& Finance. Journal of Property Investment \& Finance, 29(6), 693-704. Retrieved from https://www.emerald.com/insight/content/doi/10.1108/14635781111171814/f ull/html

Lykkesfeldt, J. (2016). Strategies for using plagiarism software in the screening of incoming journal manuscripts: recommendations based on a recent literature survey. Basic \& clinical pharmacology \& toxicology, 119(2), 161-164. https:// doi.org/10.1111/bcpt.12568

Martin, D. F. (2005). Plagiarism and technology: A tool for coping with plagiarism. Journal of education for business, 80(3), 149-152. https:// doi.org/10.3200/JOEB.80.3.149-152

Masic, I. (2011). How to search, write, prepare and publish the scientific papers in the biomedical journals. Acta Informatica Medica, 19(2), 68. https://doi.org/10.5455/aim.2011.19.68-79

Masic, I., Mornjakovic, Z., Šuško, I., \& Cosovic, E. (2004). Citiranje i navodjenje literature u biomedicini. Acta Inform Med, 12(3-4), 91-95.

Masters, E. A. (2013). Research Misconduct in National Science Foundation Funded Research: A Mixed-Methods Analysis of 2007-2011 Research Awards. ProQuest LLC. Retrieved from https://eric.ed.gov/?id=ED550845

McDowell, L., \& Liardét, C. L. (2019). Japanese materials scientists' experiences with English for research publication purposes. Journal of English for Academic Purposes, 37, 141-153. https://doi.org/10.1016/j.jeap.2018.11.011

Mohammadi, R., Nikokalam, M., Bastani, P., Ghalaneh, S., Abhari, S., \& Garavand, A. (2018). Citation and Content Analysis of Journal of Health Management and Informatics in 2014-2016. Journal of Health Management and Informatics, 5(2), 72-77. Retrieved from https://jhmi.sums.ac.ir/article_42708.html

Morrison, H. (2017). From the field: Elsevier as an open access publisher. The Charleston Advisor, 18(3), 53-59. https://doi.org/10.5260/chara.18.3.53

Mungra, P., \& Webber, P. (2010). Peer review process in medical research publications: Language and content comments. English for Specific Purposes, 29(1), 43-53. https://doi.org/10.1016/j.esp.2009.07.002

Naik, R. R., Landge, M. B., \& Mahender, C. N. (2015). A review on plagiarism detection tools. International Journal of Computer Applications, 125(11). Retrieved from http:/ / citeseerx.ist.psu.edu/viewdoc/download?doi=10.1.1.695.3835\&rep=rep1 \&type $=$ pdf

Nair, P. R., \& Nair, V. D. (2014). Organization of a research paper: The IMRAD format. In Scientific writing and communication in agriculture and natural resources (pp. 13-25). Springer, Cham. https://doi.org/10.1007/978-3-319-03101-9_2

Ojha, P. K., Ismail, A., \& Kuppusamy, K. S. (2018). Perusal of readability with focus on web content understandability. Journal of King Saud University-Computer and Information Sciences, 32(10), 1221. https:// doi.org/10.1016/j.jksuci.2018.03.007

Otto, J., \& Partow-Navid, P. Doshi., M.(2010). Revisiting the readability of management information systems journals again. Research in Higher Education Journal, 1-7. Retrieved from http://citeseerx.ist.psu.edu/viewdoc/download?doi=10.1.1.651.3\&rep=rep1\&ty $\mathrm{pe}=\mathrm{pdf}$ 
Pawlak, M. (2020). Grammar learning strategies as a key to mastering second language grammar: A research agenda. Language Teaching, 53(3), 358-370. https://doi.org/10.1017/S0261444819000314

Pimm, J. (2013). Dear Editor, why have you rejected my article?. The psychiatrist, 37(10), 313-314. https://doi.org/10.1192/pb.bp.113.044784

Plavén-Sigray, P., Matheson, G. J., Schiffler, B. C., \& Thompson, W. H. (2017). The readability of scientific texts is decreasing over time. Elife, 6, e27725. https://doi.org/10.7554/eLife.27725.001

Radianti, J., Majchrzak, T. A., Fromm, J., \& Wohlgenannt, I. (2020). A systematic review of immersive virtual reality applications for higher education: Design elements, lessons learned, and research agenda. Computers \& Education, 147, 103778. https:/ / doi.org/10.1016/j.compedu.2019.103778

Rauhvargers, A. (2011). Global university rankings and their impact. Leadership for WorldClass Universities Challenges for Developing Countries, (June). Retrieved from

http://www.ehea.info/media.ehea.info/file/EUA_seminar_June_2011/76/5/R ankings_Seminar_Rauhvargers_Presentation_of_Report_607765.pdf

Reed, J., Deakin, L., \& Sunderland, T. (2015). What are 'Integrated Landscape Approaches' and how effectively have they been implemented in the tropics: a systematic map protocol. Environmental Evidence, 4(1), 2. Retrieved from https:/ / environmentalevidencejournal.biomedcentral.com/articles/10.1186/20 47-2382-4-2

Roe, D., Fancourt, M., Sandbrook, C., Sibanda, M., Giuliani, A., \& Gordon-Maclean, A. (2014). Which components or attributes of biodiversity influence which dimensions of poverty?. Environmental Evidence, 3(1), 3. https:/ /link.springer.com/article/10.1186/2047-2382-3-3

Rozovskaya, A., \& Roth, D. (2010, October). Generating confusion sets for contextsensitive error correction. In Proceedings of the 2010 Conference on Empirical Methods in Natural Language Processing (pp. 961-970). Association for Computational Linguistics. Retrieved from https://www.aclweb.org/anthology/D10-1094.pdf

Salkind, N. J. (Ed.). (2010). Encyclopedia of research design (Vol. 3). Sage.

Salmi, J. (2009). The challenge of establishing world class universities. The World Bank.

Setyawan, A., Aznam, N., Paidi, P., \& Citrawati, T. (2020). Influence of the use of technology through problem based learning and Inkuiri models are leading to scientific communication students class VII. Journal of Technology and Science Education, 10(2), 190-198. http:/ / dx.doi.org/10.3926/jotse.962

Severance, S. J., \& Cohen, K. B. (2015). Measuring the readability of medical research journal abstracts. Proceedings of BioNLP 15, 127-133. https://www.aclweb.org/anthology/W15-3815.pdf

Sharma, B. B., \& Singh, V. (2011). Ethics in writing: Learning to stay away from plagiarism and scientific misconduct. Lung India: Official Organ of Indian Chest Society, 28(2), 148. 10.4103/0970-2113.80337

Simonsohn, U., Nelson, L. D., \& Simmons, J. P. (2014). P-curve: a key to the file-drawer. Journal of Experimental Psychology: General, 143(2), 534. https://doi.org/10.1037/a0033242

Singh, V., \& Mayer, P. (2014). Scientific writing: strategies and tools for students and advisors. Biochemistry and Molecular Biology Education, 42(5), 405-413. https://doi.org/10.1002/bmb.20815

Song, F., Parekh, S., Hooper, L., Loke, Y. K., Ryder, J., Sutton, A. J., ... \& Harvey, I. (2010). Dissemination and publication of research findings: an updated review of 
related biases. Health Technol Assess, 14(8), 1-193. Retrieved from http:/ / citeseerx.ist.psu.edu/viewdoc/download?doi=10.1.1.800.2284\&rep=rep1 \&type $=$ pdf

Štajner, S., Evans, R., Orasan, C., \& Mitkov, R. (2012). What can readability measures really tell us about text complexity. In Proceedings of workshop on natural language processing for improving textual accessibility (pp. 14-22). Retrieved from

http:/ / citeseerx.ist.psu.edu/viewdoc/download?doi=10.1.1.353.9628\&rep=rep1 \&type $=$ pdf\#page $=19$

Stivers, J., \& Cramer, S. F. (2017). From rejected to accepted: Part 2 -Preparing a rejected manuscript for a new journal. The Journal of Faculty Development, 31(2), 63-65.

Stout, D. E., Rebele, J. E., \& Howard, T. P. (2006). Reasons research papers are rejected at accounting education journals. Issues in Accounting Education, 21(2), 81-98. https:// doi.org/10.2308/iace.2006.21.2.81

Stretton, S., Bramich, N. J., Keys, J. R., Monk, J. A., Ely, J. A., Haley, C., ... \& Woolley, K. L. (2012). Publication misconduct and plagiarism retractions: a systematic, retrospective study. Current medical research and opinion, 28(10), 1575-1583. https:// doi.org/10.1185/03007995.2012.728131

Sullivan, G. M. (2015). What to do when your paper is rejected.

Swales, J. (1990). Genre analysis: English in academic and research settings. Cambridge University Press.

Tetreault, J. R., \& Chodorow, M. (2008, August). The ups and downs of preposition error detection in ESL writing. In Proceedings of the 22nd International Conference on Computational Linguistics-Volume 1 (pp. 865-872). Association for Computational Linguistics. https://www.aclweb.org/anthology/C08-1109.pdf

Tincani, M., \& Travers, J. (2019). Replication research, publication bias, and applied behavior analysis. Perspectives on Behavior Science, 42(1), 59-75. Retrieved from https://link.springer.com/article/10.1007/s40614-019-00191-5

Tunlid, A., Kristoffersson, U., \& Åström, F. (2020). A century of Hereditas: from local publication to international journal. Hereditas, 157(1), 1-19. https://link.springer.com/article/10.1186/s41065-020-00164-8

Uzuner, S. (2008). Multilingual scholars' participation in core/global academic communities: A literature review. Journal of English for Academic Purposes, 7(4), 250-263. https://doi.org/10.1016/j.jeap.2008.10.007

van Nunen, K., Li, J., Reniers, G., \& Ponnet, K. (2018). Bibliometric analysis of safety culture research. Safety Science, 108, 248-258. https:// biblio.ugent.be/publication/8529724

Wager, E., \& Kleinert, S. (2010). Responsible research publication: international standards for authors. Promoting Research Integrity in a Global Environment. Singapore, 309-16. 